\title{
Registos clínicos: pedra angular na qualidade da prestação de cuidados de saúde
}

Conceição Outeirinho*

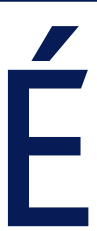

reconhecido que os registos clínicos são essenciais para o exercício de uma medicina de qualidade sendo uma ferramenta fundamental para a gestão clínica. Devem refletir o mais fielmente possível o estado de saúde da pessoa, funcionando como um veículo de comunicação efetiva, rigorosa e completa sobre os factos relevantes. Só com estes pressupostos podemos fazer uma medicina de qualidade, salvaguardar o erro médico, acautelar a proteção médico-legal e promover o desenvolvimento e a investigação clínica.

Este assunto tem andado um pouco afastado das preocupações dos profissionais e, diria mesmo, da gestão, com qualidade, da prática clínica. Parece haver algum descuro nos registos clínicos que reflitam o estado de saúde atualizado do paciente, porquanto o foco de atenção se encontra mais centrado na codificação/classificação das doenças ou procedimentos, nos tempos e locais próprios que servem a leitura de indicadores pelos módulos estatísticos indispensáveis ao processo de contratualização com reflexo, em muitos casos, na remuneração das equipas de saúde. ${ }^{1}$

Há, pois, a necessidade de que os médicos se mantenham atualizados sobre os métodos de registo clínico e utilizem corretamente o mais adequado ao contexto da sua prática e conheçam os processos disponíveis para melhorar o registo da informação clínica dos pacientes.

Assim, impõe-se centrar a atenção na qualidade dos registos clínicos com objetivo de melhorar e contribuir para a redução do erro em Medicina, melhorar a prestação de cuidados aos nossos pacientes e promover uma adequada partilha de informação relevante, pre-

*Médica de família. USF Garcia de Orta, ACeS Porto Ocidental. Professora auxiliar convidada. Instituto de Ciências Biomédicas Abel Salazar, Universidade do Porto. cisa e atualizada sobre o seu estado de saúde entre os diferentes profissionais dos diversos níveis de cuidados de saúde. ${ }^{1}$

A centralidade dos cuidados no paciente exige também que se reoriente o registo clínico neste sentido.

O Despacho n. ${ }^{\circ} 2.784 / 2013$, publicado no Diário da República, 2. ${ }^{\text {a }}$ série, n. ${ }^{\circ}$ 36, de 20 de fevereiro, chama a atenção para "os estudos que apontam para o aumento do risco clínico e erro em Medicina com a falta de circulação de informação clara e atempada entre todos os intervenientes no processo de prestação de cuidados de saúde, e da necessidade de promoção da melhoria dos registos electrónicos de dados de saúde e a sua partilha a nível nacional, como instrumentos fundamentais de melhoria dos cuidados prestados à população". No seu ponto 4 refere, nomeadamente, que se deve garantir "que a informação clínica é registada, exclusivamente, em suporte electrónico, e que o resumo clínico único (RCU) do utente, quando disponível na PDS, é atualizado em todos os utentes."Este despacho refere também a necessidade de auditorias periódicas aos registos.

Encontramos, ainda, recomendações sobre procedimentos nos registos clínicos informáticos em circulares normativas e documentos do Ministério da Saúde. ${ }^{2-3}$ Porém, estas são muitas vezes feitas de modo avulso e mais orientadas para a gestão e não para o paciente.

Não é apenas a força da legislação ou outros documentos normativos que fazem a mudança de práticas e promovem a optimização de procedimentos. A sensibilidade, o conhecimento, as competências e as atitudes, com melhoria contínua, dos profissionais é que são motor fundamental para o atingimento desse desiderato.

Assistimos, no final de 2017, despoletado por médicos de família ligados também à academia, à aborda- 
gem e à reflexão interpares (Encontro Nacional da ADSO) sobre o paradigma dos registos clínicos e premência da sua evolução e aperfeiçoamento.

Para trabalharmos a questão da qualidade dos registos clínicos há que ter em conta três grandes linhas de intervenção: a formação, a prática clínica e os sistemas informáticos. ${ }^{1}$

Na primeira - Formação - há que focar a atenção em três áreas:

1. No ensino pré-graduado, com formação básica sobre registos clínicos, metodologia a adoptar em função do tipo de prestação de cuidados e da área médica envolvida. É reconhecido na comunidade científica e académica que o registo médico orientado por problemas (RMOP), proposto por Lawrence Weed $^{4}$ nos anos setenta do século XX, é o mais adequado no âmbito da prestação dos cuidados longitudinais e contínuos e, por isso mesmo, adotado no âmbito da medicina geral e familiar. Nesta fase, para além da obtenção do conhecimento do método, importa saber o porquê da sua utilização e treinar a sua aplicabilidade.

2. No ensino pós-graduado, com a revisitação dos conceitos, desenvolvimento e melhoria das competências e atitudes neste domínio. Orientando para a importância dos registos que salvaguardem a medicina centrada no paciente, a gestão clínica, a investigação e o desenvolvimento.

3. Na formação e atualização contínua dos profissionais. Mas enquanto na primeira área o grande objetivo é a tomada de conhecimento e o treino básico, nas duas últimas, e porque a formação se faz em exercício, a atenção recai na adequação e no rigor dos registos, na utilização, correta, das classificações ${ }^{5-6} \mathrm{de}$ doenças padronizadas e validadas, quer ao nível do processo do doente (Notas Clínicas Progressivas e Lista de Problemas) quer nas plataformas informáticas de interface entre os diferentes níveis e os diversos prestadores de cuidados.

Na segunda linha-a prática clínica-, a intervenção deverá ser feita através:

1. Da promoção da otimização dos registos clínicos informáticos pelos clínicos, atendendo, pelo menos, aos seguintes aspetos: registos informativos sobre o real estado de saúde do doente, quer no que respeita à sua apresentação, identificação dos seus pro- blemas de saúde e seu grau de resolução no momento, bem como um plano de intervenção bem delineado a curto, médio e longo prazo; garantia da existência de registos clínicos atuais, fiáveis e reais; adequada classificação $0^{5-6}$ de problemas de saúde do doente com a utilização da ICPC nas Notas Clínicas Progressivas - no item A do SOAP e lista de problemas; atualização periódica e regular da Lista de Problemas (Problemas ativos e Problemas passivos); atualização do RCU (RCU2); ajuste do tempo de consulta, para realizar adequadamente $o \ll 7^{\circ}$ passo da consulta» ${ }^{7}$, revendo e completando os registos clínicos; prever tempo para esta tarefa no horário semanal de trabalho.

2. Do desenvolvimento e implementação de planos de qualidade organizacional neste âmbito, que atendam aos procedimentos do ciclo da melhoria contínua da qualidade.

Por fim e dada a sua relevância no processo, temos

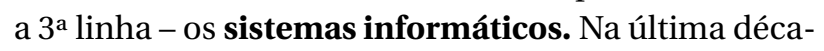
da, o desenvolvimento das plataformas informáticas, no âmbito do SNS, foi notável; todavia, há ainda muito a desenvolver e a aperfeiçoar neste campo. A sua implementação levou a uma melhoria global no registo e a uma redução dos custos. Para a primeira contribuiu a legibilidade e a gestão mais eficaz de grande volume de informação, a melhoria da acessibilidade aos dados, a maior capacidade de armazenamento, a possibilidade de fazer cópias de segurança, a facilidade de arquivo e a versatilidade (usar códigos de diferentes utilizadores).

Tem havido ao longo do tempo, embora lento e não uniforme a nível nacional, o desenvolvimento da possibilidade da interface com outros programas e registos, permitindo a troca de informação, o acompanhamento do processo, a organização de atividades, a análise estatística da informação, possibilitando uma gestão clínica mais acurada e a interface com outros prestadores e níveis de cuidados. Tudo isto reverteu a favor da redução de custos, quer para o doente quer para as instituições de saúde. Porém, necessitamos de desenvolver e de melhorar ainda mais os sistemas informáticos, não só em aspetos como aqueles que se prendem com a velocidade de acesso, a limitação temporal no acesso aos dados, a confidencialidade dos mesmos, a morosidade de registo ou a interface com 
outras instituições, mas também ao nível dos próprios registos clínicos. ${ }^{1} \mathrm{E}$, aqui, reforço de novo a necessidade da aplicabilidade da medicina centrada no paciente.

Em concreto será necessário acautelar espaço para o registo de problemas de saúde de modo mais completo e não apenas a sua mera classificação/codificação e tornar possível, a todo o tempo, que essa informação esteja acessível a qualquer profissional de saúde que cuide da pessoa, independentemente do contexto da prática e do nível de prestação de cuidados de saúde. Os módulos estatísticos deverão ser desenvolvidos recentrando-se e servindo a investigação clínica e não apenas a aferição de procedimentos que levam ao cumprimento de metas que suportam a contratualização.

A aposta na melhoria e na qualidade dos registos clínicos vai requerer a colaboração e a complementaridade de várias forças, a academia, as associações científicas dos profissionais, os próprios profissionais no terreno e os informáticos. O seu trabalho conjunto, articulado, complementar e contínuo contribuirá por certo para o objetivo final: a prestação de serviços de saúde adequados, eficientes com o exercício de uma medicina de qualidade e personalizada.

\section{REFERÊNCIAS BIBLIOGRÁFICAS}

1. Outeirinho C. Qualidade dos registos clínicos: qualidade na prestação de cuidados de saúde, melhor governação clínica. J Med Fam. 2017;4(8):10-1.

2. Administração Central do Sistema de Saúde. Recomendações para a utilização da Classificação Internacional de Cuidados de Saúde Primários (ICPC) na prática clínica diária em Unidades do SNS: circular normativa n. ${ }^{\circ}$ 20/2014/DPS/ACSS, de 16.07.2014 [Internet]. Lisboa:ACSS; 2014. Available from: http://www2.acss.min-saude.pt/Portals/0/cn20.pdf

3. Administração Central do Sistema de Saúde. Bilhete de identidade dos indicadores de contratualização dos cuidados de saúde primários propostos para o ano de 2016: ACES (USF, UCSP e UCC) [Internet]. Lisboa:ACSS; 2016. Available from: http://www2.acss.min-saude.pt/Portals/0/bilhete_identidade_indicadores_contratualizacao_2016__2016_02_16.pdf

4. Weed LL. Medical records that guide and teach. N Eng J Med. 1968;278(11):593-600.

5. Pinto D. O que classificar nos registos clínicos com a Classificação Internacional de Cuidados Primários? [What should we code in health records with the International Classification of Primary Care?]. Rev Port Med Geral Fam. 2014;30(5):328-34. Portuguese

6. Pinto D. Classificar motivos de consulta e procedimentos com a ICPC na prática clínica? [Classifying reasons for encounter and procedures with ICPC in clinical practice?]. Rev Port Med Geral Fam. 2012;28(4): 247-8. Portuguese

7. Ramos V. A consulta em 7 passos: execução e análise crítica de consultas em medicina geral e familiar. Lisboa:VFBM Comunicação; 2008. ISBN 9789898160225

ENDEREÇO PARA CORRESPONDÊNCIA

couteirinho@gmail.com 